Check for updates

London, UK

Cite this as: $B M J 2022 ; 376: 0366$ http://dx.doi.org/10.1136/bmj.0366 Published: 22 February 2022

\section{A window to patient health: the consultant dermatologist}

The consultant dermatologist speaks to Kathy Oxtoby about how his chosen specialty makes him happy, and how his mentors have inspired him

Kathy Oxtoby

Doctors are often asked what they find inspirational or enjoyable about their specialty, but for Daniel Keith, a consultant dermatologist at North Bristol NHS Trust, there's a more meaningful question.

"I was on a career panel at a conference and a student asked, 'If I became a dermatologist, what would make me happy?'

“It's an interesting question-it's not the same as asking what you enjoy about your job. What makes you happy speaks more to our overall sense of fulfilment," he says.

His answer? "It's the people you meet."

Keith explains, "The impact of skin disease is underestimated. By the time your patient walks into your clinic they will usually have seen many different healthcare professionals, waited a long time, and had their problem belittled and dismissed.

"You might be the first person they've talked to about their problem who's taking it seriously. And that's all they need at that moment-for you to listen and take them seriously.

"So, I told the student, 'If you feel you're the sort of person who can take a reward from being this type of doctor you'll find happiness in a career in dermatology.",

Keith grew up "interested in science, biology, and nature" and says he always wanted to be a doctor, even though his father (a GP) and his mother (a nurse) "tried to put me off."

In 2003 he started studying medicine at Oxford University Medical School. His dermatology rotation "was brief and hurried, which I discovered was quite common to all medical schools."

It was his general medical placement at Northampton General Hospital that first inspired him to consider dermatology, where he was "struck by how everyone in the dermatology team was so happy and enthusiastic."

Keith did his higher specialty training at University Hospitals Bristol NHS Trust where he was inspired by Cameron Kennedy, whom he found "a kind and patient teacher," and one incident in particular reminds him why he chose dermatology.

"We had a patient with a very rare condition. I asked Cameron to review them and tell me what the answer was-I had no idea what was going on.

"After a while of looking at the patient Cameron looked at me and said, 'I've no idea what this is. I've never seen anything like it.' And he was really excited about that fact.
"I relayed this story to another consultant who said, 'That's why dermatology is such a great specialty-because one day you'll be as experienced as Cameron and still, every week, you will see something you've never seen before.' And so far it's true."

He attributes this variety to the nature of skin being "a window on to the rest of the health of a person."

A substantive NHS consultant at North Bristol NHS Trust since 2017, Keith tries to channel his role model Cameron's enthusiasm and patience when teaching his own trainees. "I often ask them to give me an opinion on a patient and I believe all consultants should do this. It not only gives trainees confidence to make suggestions and develop their own decision making, but also helps me question my own decisions and learn from them," he says.

Keith's main interests are skin cancer and dermatological surgery-and lasers, which he feels "are going to play an increasing role in the future of dermatology." He says, "I find using that cutting edge of technology to help patients brings back my passion for real science, which is the reason we go into medicine in the first place."

Outside work he enjoys a rural life in Gloucestershire with his family and seven recently adopted chickens, finds gardening and growing food therapeutic, and has a love for nature photography.

Whether or not students and trainees opt for dermatology, Keith hopes he will inspire them to recognise the impact skin disease has on their patients. When making their career choice he advises them to consider "what would make you happy" and "to look for variety, as doing different things every day keeps you looking forward and keeps you fresh."

\section{Nominated by Victoria Vilenchik}

"Since day one of my job, Daniel has looked after me, supervised me, given me constructive feedback, and, most importantly, continued to support me in my learning and career progression.

"He has always been honest and reflected on his own experiences in order to help me succeed.

"He has instilled confidence in me that I had never had before. Most importantly, he has remained a good friend and colleague following my departure to a different trust as part of training."

Victoria Vilenchik is an internal medicine trainee stage 2, intensive care unit, at Southmead Hospital, Bristol

To nominate someone who has been a role model during your medical career, send their name, job title, and the reason for your nomination to awaters@bmj.com 